\title{
Evidence of partially preserved endothelial dilator function in diseased coronary arteries
}

\author{
D Tousoulis, C Tentolouris, T Crake, C Stefanadis, P Toutouzas, G Davies
}

\begin{abstract}
Objective-To examine the effects of substance $\mathbf{P}$ (endothelium dependent vasodilator) and glyceryl trinitrate (endothelium independent vasodilator) on epicardial coronary arteries in patients with normal coronary angiograms and patients with coronary artery disease.

Design-Intracoronary infusions of normal saline, the receptor mediated nitric oxide stimulant substance $P$ (5.6 and 27.8 $\mathrm{pmol} / \mathrm{min}$ each for five minutes), and glyceryl trinitrate ( $250 \mu \mathrm{g}$ bolus) were given in 24 patients with coronary artery disease and stable angina, and in nine patients with normal angiograms. The diameter of proximal and distal coronary segments was measured by computerised quantitative angiography
\end{abstract}

Results-Proximal segments of patients with coronary artery disease dilated less than those of patients with normal angiograms in response to $27.8 \mathrm{pmol} / \mathrm{min}$ substance P (mean (SEM): 7.9 (1.3)\% $v 15$ $(2.3) \%$ respectively, $p<0.01)$. The proximal segments of diseased arteries also dilated less than those of "normal" arteries in response to glyceryl trinitrate $\mathbf{( 1 0 . 2}$

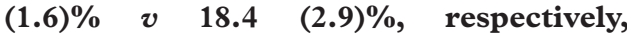
p $<0.01)$. The responses of distal segments to substance $P$ and glyceryl trinitrate were similar in the two patient groups. There were correlations (all $p<0.001)$ between the coronary diameter after substance $P$ and after glyceryl trinitrate in normal proximal segments $(r=0.94)$ and normal distal segments $(r=0.64)$, in diseased proximal segments $(r=0.95)$ and diseased distal segments $(r=0.89)$, and for coronary stenoses $(r=0.93)$.

Conclusions-Proximal segments of patients with coronary disease dilated less than the proximal segments of "normal" patients in response to substance $P$ and glyceryl trinitrate. The response to substance $P$ is substantial and closely correlated with the response to glyceryl trinitrate in both "normal" patients and those with coronary disease. This suggests that although the proximal segments of diseased coronary arteries have a reduced capacity to dilate in response to direct stimulation of smooth muscle cell relaxation, they retain much of their endothelium dependent vasodilator function. (Heart 1999;82:471-476)

Keywords: endothelium; nitric oxide; coronary artery disease; glyceryl trinitrate
The endothelium influences vascular tone by the release of various relaxing and constricting factors which modulate the contractile activity of the underlying smooth muscle. ${ }^{1-3}$ Endothelium derived relaxing factor (EDRF) is one of the mediators of vascular smooth muscle relaxation. ${ }^{4-9}$ Previous studies have shown that vasodilatation mediated by the release of EDRF is markedly impaired in patients with coronary artery disease and hypertension. ${ }^{10-13}$ This phenomenon may precede the development of visible atherosclerosis ${ }^{14}$ and contribute to the pathogenesis of vascular complications in patients with atherosclerosis. ${ }^{15}$ However, Schachinger and Zeiher ${ }^{16}$ have recently shown that basal vasomotor tone is reduced at the site of atheromatous plaques.

Ludmer et al showed that acetylcholine causes dilatation of normal and constriction of diseased epicardial coronary arteries. ${ }^{11}$ However, acetylcholine has a dual effect on vascular tone: relaxation owing to the release of EDRF and constriction owing to direct smooth muscle cell stimulation. ${ }^{1}$ Substance $\mathrm{P}$ is a more selective endothelium dependent dilator than acetylcholine. In vitro, relaxation induced by substance $\mathrm{P}$ is dependent on the presence of intact endothelial cells and it does not directly affect coronary smooth muscle tone. ${ }^{10-21}$ In vivo, intracoronary substance $\mathrm{P}$ has been shown to dilate normal epicardial coronary arteries and to reduce the coronary vascular resistance. ${ }^{22} 23$ In the present study the intracoronary administration of substance $\mathrm{P}$ and glyceryl trinitrate was used to investigate both endothelium dependent and endothelium independent vasodilatation of epicardial coronary arteries and stenoses in patients with normal coronary angiograms and patients with coronary artery disease.

\section{Methods}

PATIENTS AND PROTOCOLS

Twenty four patients (20 male, four female, mean (SEM) age 58 (7) years) with chronic stable angina and coronary artery disease, and nine patients (four male, five female, mean age 53 (8) years) with atypical chest pain and normal coronary arteries were studied. All patients with chronic stable angina had a positive treadmill exercise test result ( $\geqslant 0.1 \mathrm{mV}$ ST segment depression) at between 5 and 7 metabolic equivalents using the modified Bruce protocol. The normal coronary arteries in the patients with atypical chest pain had a smooth angiographic outline in multiple projections with no irregularity or stenosis. As intravascular ultrasound information was unavailable it is not possible to exclude the presence of mild 
Table 1 Reactivity of proximal and distal segments and coronary stenoses to substance $P$ and glyceryl trinitrate in patients with normal angiograms and in patients with stable angina

\begin{tabular}{|c|c|c|c|c|c|}
\hline & \multicolumn{5}{|c|}{ Minimum luminal diameter ( $\mathrm{mm}$ ) } \\
\hline & Saline 1 & Substance $P(5.6 \mathrm{pmol})$ & Substance P $(27.8 \mathrm{pmol})$ & Saline 2 & Glyceryl trinitrate \\
\hline \multicolumn{6}{|l|}{ Stable angina } \\
\hline Proximal $(n=50)$ & $3.10(0.09)[0.7(0.2) \%]$ & $3.19(0.10)[7.3(1.4) \%]$ & $3.28(0.09)[7.9(1.3) \%]$ & $3.12(0.09)[1.1(0.2) \%]$ & $3.35(0.09)[10.2(1.6) \%]$ \\
\hline Distal $(\mathrm{n}=59)$ & $1.35(0.04)[1.0(0.3) \%]$ & $1.52(0.05)[13.9(1.9) \%]^{\star}$ & $1.54(0.05)[16.1(1.6) \%]^{\star}$ & $1.37(0.04)[1.5(0.3) \%]$ & $1.64(0.05)[21.5(1.7) \%]^{\star}$ \\
\hline Stenoses $(n=28)$ & $1.56(0.08)[1.1(0.3) \%]$ & $1.68(0.10)[9.6(1.5) \%]$ & $1.74(0.10)[11.9(1.8) \%]$ & $1.58(0.08)[1.4(0.3) \%]$ & $1.79(0.10)[16.3(1.8) \%]^{\star \star}$ \\
\hline \multicolumn{6}{|c|}{ Normal coronary arteries } \\
\hline Proximal $(n=19)$ & $3.03(0.16)[0.4(0.4) \%]$ & $3.33(0.16)[11.5(2.3) \%]$ & $3.43(0.23)[15.0(2.3) \%] \dagger$ & $3.07(0.16)[1.1(0.4) \%]$ & $3.53(0.24)[18.4(2.9) \%] \dagger$ \\
\hline Distal $(n=27)$ & $1.48(0.04)[0.3(0.5) \%]$ & $1.68(0.05)[14.5(2.2) \%]$ & $1.71(0.05)[15.9(1.6) \%]$ & $1.50(0.04)[0.9(0.5) \%]$ & $1.74(0.06)[18.5(2.7) \%]$ \\
\hline
\end{tabular}

Values are mean (SEM); percentage change from baseline given in square brackets.

${ }^{\star} \mathrm{p}<0.01 v$ proximal segments; $\dagger \mathrm{p}<0.01 v$ stable angina; ${ }^{\star \star} \mathrm{p}<0.01 v$ substance $\mathrm{P}$ responses.

Saline 1 , first saline infusion; saline 2 , second saline infusion.

atheroma in these angiographically "normal" arteries.

Patients were excluded from the study if they had diabetes mellitus, recent myocardial infarction ( $<6$ months), left ventricular hypertrophy (on echocardiography), left ventricular dysfunction (left ventricular ejection fraction $<50 \%$ ), or valvar heart disease.

Antianginal drug treatment was stopped 24 hours before the study. The patients were allowed to use sublingual glyceryl trinitrate as necessary, but no study was performed within three hours of its administration.

Following the diagnostic coronary angiogram, an optimal radiographic projection was selected and kept constant for subsequent angiograms. Two ECG leads were monitored continuously throughout the study. All patients received a single two minute infusion of $0.9 \%$ saline $(2 \mathrm{ml} / \mathrm{min})$ followed by a five minute infusion of incremental doses of substance $\mathrm{P}$ ( 5.6 and $27.8 \mathrm{pmol} / \mathrm{min}$ ) in saline, followed by a two minute infusion of $0.9 \%$ saline (2 $\mathrm{ml} / \mathrm{min}$ ), using a syringe pump, followed by an intracoronary bolus dose of glyceryl trinitrate (250 $\mu \mathrm{g}$ in $2 \mathrm{ml}$ of saline).

Femoral arterial pressure and heart rate were recorded during the last 30 seconds of each infusion period. Angiography was performed with a hand injection of 6-8 $\mathrm{ml}$ non-ionic contrast medium at baseline, immediately after each infusion, and two to three minutes after glyceryl trinitrate. Before each angiogram, the catheter was emptied to avoid bolus administration of the infusate.

The protocols were approved by the research ethics committee and each patient gave written informed consent.

QUANTITATIVE CORONARY ANGIOGRAPHY

The arterial segments in each frame were analysed in random order using quantitative computerised analysis with an automated edge contour detection analysis system (Computerized Angiographic Analysis System, Version 2V2; Pie Data Medical, Maastricht, Netherlands). ${ }^{2425}$ End diastolic frames from each arteriogram were selected for analysis. The angiographic catheter was used as a scaling device and this, together with pincushion-distortion correction, allowed the diameters to be recorded as absolute values (expressed in millimetres). Recorded variables at baseline and after saline, substance $\mathrm{P}$, and nitrate administration were the luminal diam- eter of proximal and distal segments containing no stenosis causing more than $20 \%$ luminal diameter reduction. The proximal left anterior descending coronary artery diameter was measured just beyond the origin of the artery and the distal diameter was measured just distal to the second diagonal branch; the proximal left circumflex coronary artery diameter was measured just beyond the origin of the artery and the distal diameter just beyond the origin of the second obtuse marginal branch; the proximal right coronary artery diameter was measured just beyond the origin of the artery and the distal diameter just beyond the posterior descending branch. A coronary stenosis was defined as an arterial segment with $>20 \%$ minimum luminal diameter reduction. The absolute diameter of the arterial segment in millimetres was measured between corresponding points on the left and right edges of the centreline. The centreline and edges were identified by a computerised algorithm. The percentage diameter reduction was calculated according to the formula:

$\% \mathrm{D}$ stenosis $=(1-\mathrm{Dm} / \mathrm{Dr}) \times 100 \%$

where $\mathrm{Dr}=$ mean diameter of the segment and $\mathrm{Dm}=$ minimum diameter of the segment. The mean diameter $\mathrm{Dr}$ was computed as the average of 11 diameter values. Quantitative analysis of coronary arteriograms was carried out by two independent observers, who reanalysed the films blindly at a remote time for reproducibility of the method. No significant intra- or interobserver variability was found (analysis of variance $\mathrm{F}=0.35, \mathrm{p}=0.82$ ).

\section{STATISTICAL ANALYSIS}

Data are expressed as mean (SEM). When serial changes in the heart rate, blood pressure, and arterial diameter were compared within the group and between the groups analysis of variance for repeated measures was used. Student's $t$ test was used to compare paired or unpaired data. Discrete data were analysed by the $\chi^{2}$ test. Probability ( $p$ ) values of $<0.05$ (two tailed) were taken to indicate statistical significance.

\section{Results}

Substance $\mathrm{P}$ reduced systolic blood pressure from 152 (4.7) to $143(5.0) \mathrm{mm} \mathrm{Hg}(\mathrm{p}<0.01)$ and increased the heart rate from 71 (1.5) to 80 (2.4) beats $/ \mathrm{min}(\mathrm{p}<0.01)$. Glyceryl trinitrate administration reduced systolic blood pressure 

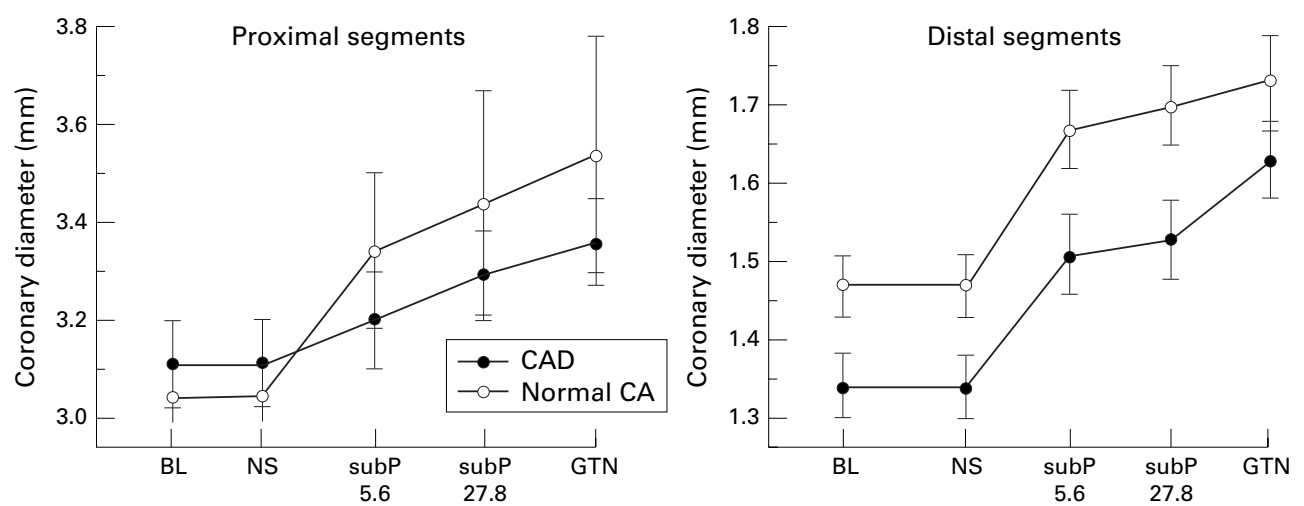

Figure 1 Plot showing mean dose dependent responses (mean coronary luminal diameter with SEM) to substance P (subP) and glyceryl trinitrate (GTN) for proximal and distal segments in patients with coronary artery disease (CAD) and in patients with "normal" coronary arteries $(C A)$. A progressive increase in mean luminal diameter occurred with increasing doses of substances $P$ and glyceryl trinitrate administration. BL, baseline; NS, saline.

from 146 (4.8) to 129 (4.5) $\mathrm{mm} \mathrm{Hg}(\mathrm{p}<0.01)$ and increased the heart rate from 73 (1.7) to 76 (1.6) beats/min (NS).

In all, we analysed 69 proximal segments (32 in the left anterior descending, 36 in the circumflex, and one in the right coronary artery), 86 distal segments (40 in the left anterior descending, 44 in the circumflex, and two in the right coronary artery), and 28 stenoses
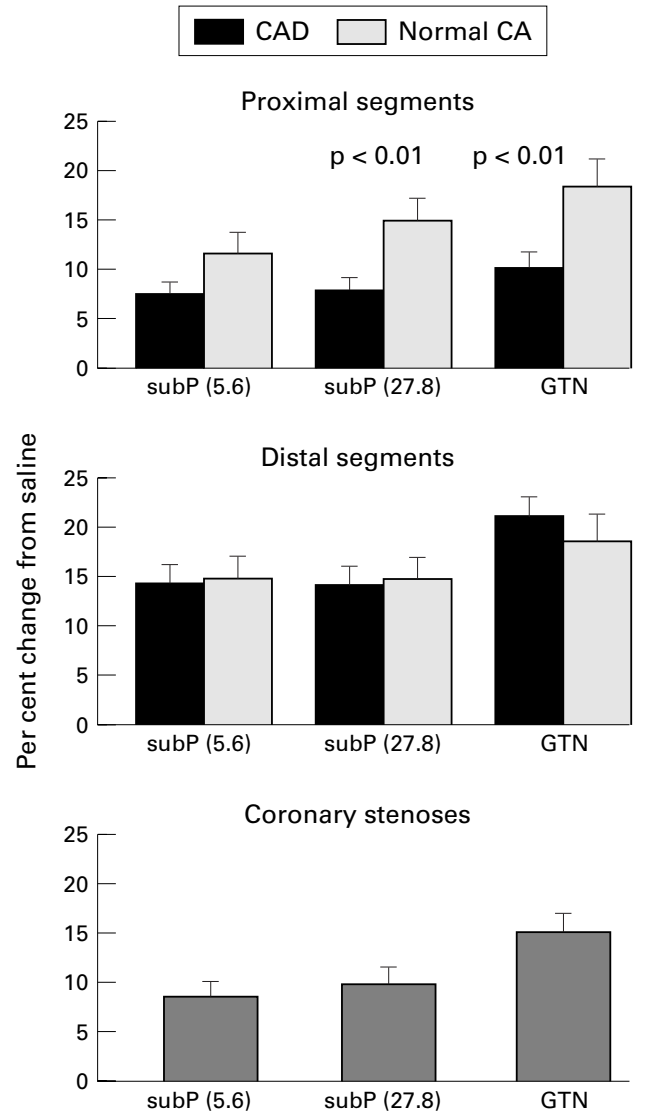

Figure 2 Bar graph showing mean (with SEM) percentage dilatation from saline after intracoronary infusion of 5.6 and $27.8 \mathrm{pmol} / \mathrm{min}$ substance $P$ (subP) and after glyceryl trinitrate (GTN) administration for proximal and distal coronary segments in patients with "normal" coronary arteries (CA) and in patients with coronary artery disease (CAD) and in coronary stenoses. In patients with normal coronary arteries, proximal segments showed a significantly greater dilatation $(p<0.01)$ during substance $P$ and glyceryl trinitrate infusions than in patients with coronary artery disease. (severity from $22 \%$ to $28 \%$ ). A progressive increase in coronary luminal diameter occurred with increasing doses of substance $\mathrm{P}$ and subsequent glyceryl trinitrate administration in both "normal" and diseased vessels (table 1, fig 1). The percentage change compared with saline was less in the proximal than in the distal segments of diseased vessels (table 1). The change in the proximal segments was less in diseased vessels than in normal vessels (figs 1 and 2). At the 5.6 pmol dose of substance $\mathrm{P}$ there was no significant effect on the proximal segments of diseased vessels, but the diameter of the proximal segments of normal vessels increased by $0.32(0.06) \mathrm{mm}$ (11.5 $(2.3) \%, p<0.01$, fig 1$)$. There was a significant correlation $(\mathrm{p}<0.001)$ between the coronary diameter after substance $\mathrm{P}$ and after glyceryl trinitrate in normal proximal segments $(r=0.94)$ and normal distal segments $(r=0.64)$, in diseased proximal segments $(r=0.95)$ and diseased distal segments $(r=0.89)$, and for coronary stenoses $(r=0.93)$ (fig 3). Regression analysis showed that the slope of this linear relation was close to unity (0.9-1.0) (fig 3).

The proximal segments of diseased coronary arteries were divided into quartiles according to their response to $27.8 \mathrm{pmol} / \mathrm{min}$ substance P. The bottom quartile showed a proximal segment response of $1.0 \quad(0.4) \%$ and distal segment response of $12.5(2.4) \%$. The top quartile showed a proximal segment response of $19(3.2) \%$ and distal segment response of $25.1(4.0) \%$. The distal segment response to substance $\mathrm{P}$ is greater than the proximal segment response in both groups $(p<0.01)$, but less in the bottom quartile than in the top quartile $(p<0.05)$. The responses of the bottom and top quartiles are shown in fig 4, together with the response of their corresponding distal segments.

\section{Discussion}

In this study we compared the effects of substance $\mathrm{P}$ with those of glyceryl trinitrate in patients with normal angiograms and in patients with coronary artery disease. There was no difference between "normal" and diseased vessels in the response of distal segments to substance P or glyceryl trinitrate. 

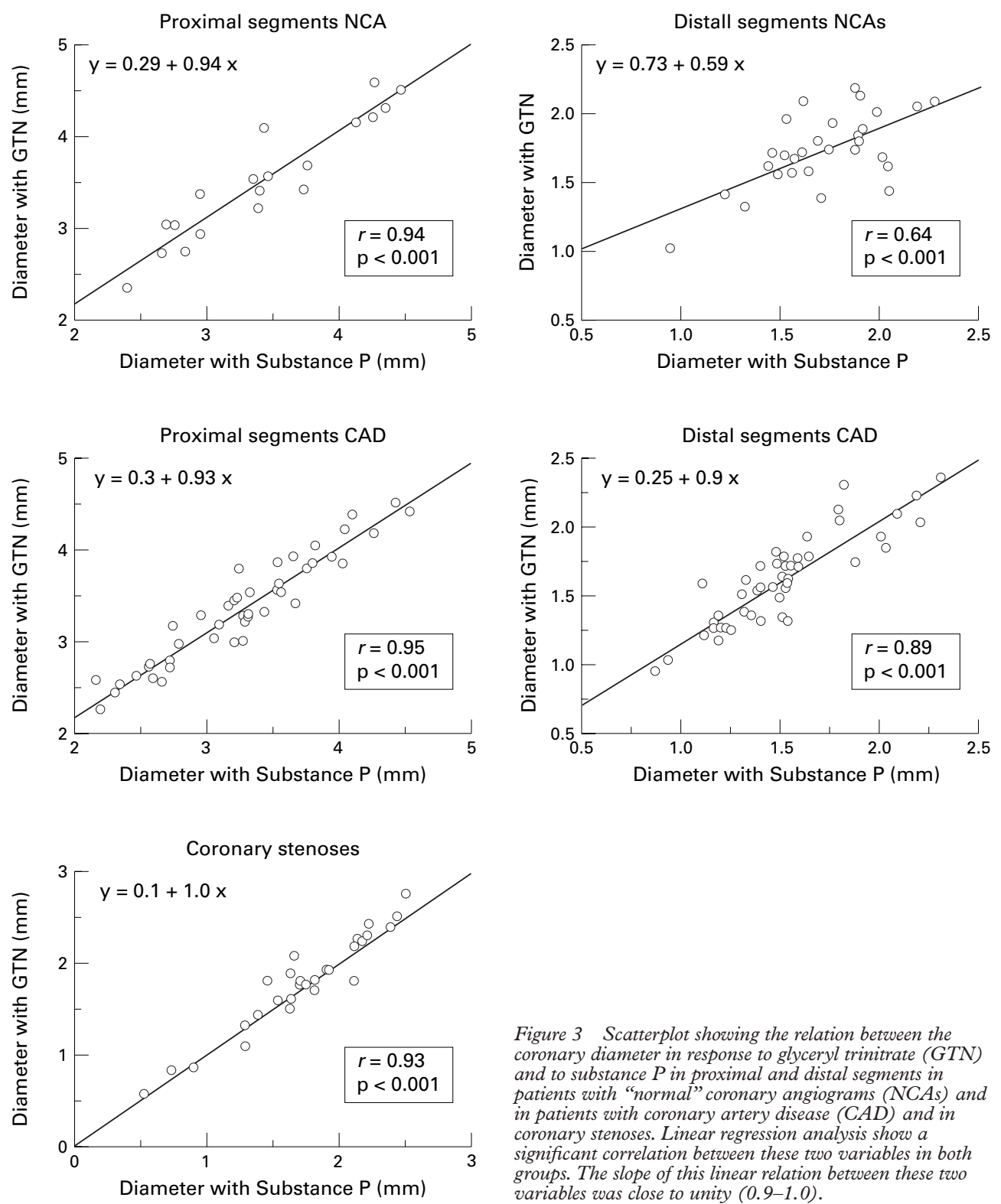

Figure 3 Scatterplot showing the relation between the coronary diameter in response to glyceryl trinitrate (GTN) and to substance $P$ in proximal and distal segments in patients with "normal" coronary angiograms (NCAs) and in patients with coronary artery disease (CAD) and in coronary stenoses. Linear regression analysis show a significant correlation between these two variables in both groups. The slope of this linear relation between these two variables was close to unity (0.9-1.0).

The proximal segments of patients with coronary disease dilated less in response to both substance $\mathrm{P}$ and glyceryl trinitrate than the proximal segments of "normal" patients. There was no significant difference in the response to substance $\mathrm{P}$ as a proportion of the glyceryl trinitrate response between stenoses $(73 \%)$ and diseased proximal segments $(77 \%)$ but both were slightly less responsive than normal proximal segments $(82 \%)$. Furthermore, there was a close correlation between the substance $P$ response and the glyceryl trinitrate response in "normal" patients and those with coronary disease. These results suggest that although the proximal segments of diseased coronary arteries including stenoses have a reduced capacity to dilate in response to direct stimulation of smooth muscle cell relaxation, much of their endothelial dilator function is preserved, as evidenced by their response to substance P. In the distal segments of diseased arteries both endothelial dilator function and the capacity to

respond to a direct smooth muscle cell relaxant stimulus are preserved.

SUBSTANCE P INDUCED VASODILATATION

Substance $P$ is a neuropeptide found in sensory neurones of the peripheral nervous system, vagus, some sympathetic ganglia, and the perivascular nerves of small arterioles in the human heart. ${ }^{26}$ It dilates both conductive and resistance vessels by an endothelium dependent mechanism that involves the production of nitric oxide and possibly also of an endothelium derived hyperpolarising factor. ${ }^{17-2127-29}$ Chester et al showed in human coronary rings that endothelium dependent relaxation in response to substance $\mathrm{P}$ and bradykinin was lost in atherosclerotic compared with normal human coronary arteries. ${ }^{30}$ The relaxation induced by substance $\mathrm{P}$ was inhibited by $\mathrm{N}^{\mathrm{G}}$-monomethyl-L-arginine, which indicates that stimulated production or release of nitric oxide is part of the mechanism of the substance 


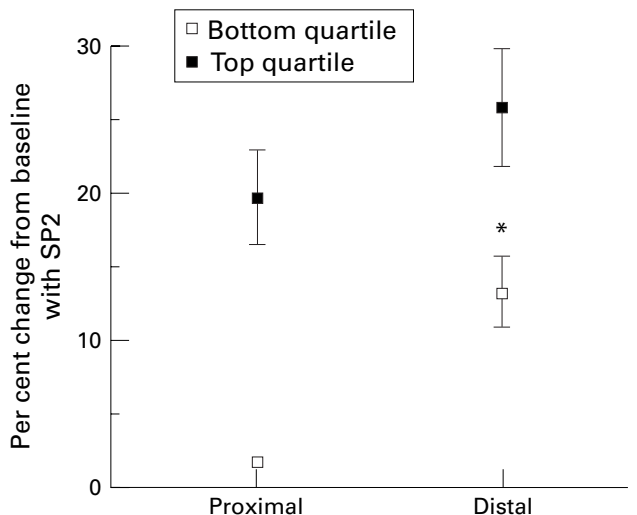

Figure 4 Graph showing per cent response to 27.8 pmol/min substance P (SP2) from baseline of the bottom and top quartiles of proximal segments together with the response of their corresponding distal segments in patients with coronary artery disease. The proximal segments of diseased coronary arteries were divided into quartiles according to their response to substance $P$. The distal segment response to substance $P$ is greater than the proximal segment response in both groups $(p<0.01)$, but less in the bottom quartile than in the top quartile $\left({ }^{\star} p<0.05\right)$.

$\mathrm{P}$ response. In addition, bradykinin has been shown to dilate atherosclerotic coronary arteries. ${ }^{31}$ However, it is possible that substance $\mathrm{P}$ has additional mechanisms of action apart from those mediated by nitric oxide and hyperpolarising factor. Crossman et al found an increase in epicardial coronary artery diameter and a significant increase in the coronary sinus blood oxygen saturation in response to intracoronary substance $\mathrm{P}$ infusion in patients with angiographically normal coronary arteries. ${ }^{22}$

Previous studies have shown that endothelial function is impaired in diseased coronary arteries $^{11} 1432$ and also in transplant recipients with angiographically normal arteries. ${ }^{33}$ The study by Ludmer et al showed that prestenotic and irregular segments of diseased coronary arteries in patients with angina constrict in response to acetylcholine, whereas segments of normal coronary arteries dilate. ${ }^{11}$ They concluded that the abnormal response to acetylcholine may represent a defect in endothelial vasodilator function and may be important in the pathogenesis of coronary vasospasm. However, their findings would be consistent with a selective defect of muscarinic receptor function and they acknowledge that the findings are also consistent with an increased sensitivity of vascular smooth muscle cells to the constrictor effect of acetylcholine. In contrast to acetylcholine, substance $\mathrm{P}$ has no direct effects on coronary smooth muscle tone and is therefore more suitable than acetylcholine for studying nitric oxide mediated vascular responses in the human coronary circulation.

It has been shown previously that atherosclerotic human coronary artery segments dilate in response to substance $\mathrm{P}^{23}$ and also to nitrates, ${ }^{34-36}$ even at the site of significant stenosis. As glyceryl trinitrate exerts its effect directly on the contractile mechanism of vascular smooth muscle cells, the observed response represents the maximum capacity of those segments to dilate and is probably a measure of the amount of functional smooth muscle that remains in that site. In a recent study, Quyyumi et al compared the effects of substance $\mathrm{P}$ and acetylcholine on coronary vasomotion. ${ }^{37}$ They found that substance $\mathrm{P}$ produced predominantly epicardial coronary dilatation (significantly greater than acetylcholine), which is consistent with our findings, and that coronary vascular dilatation induced by substance $P$, like that with acetylcholine, is at least partly caused by the release of nitric oxide because its effects were inhibited by $\mathrm{N}^{\mathrm{G}}$-monomethyl-L-arginine. A previous study ${ }^{38}$ has shown significant preservation of the dilator response to glyceryl trinitrate in diseased human epicardial coronary arteries. However, we $e^{36}$ and others ${ }^{39}{ }^{40}$ have found a decreased vasodilator response to nitrates in the proximal segments of patients with coronary artery disease, consistent with the findings of the present study. Patients with coronary artery disease may also have impaired coronary vasomotor tone at baseline. ${ }^{16}$ These differences may reflect differences in the study populations or in the location of segments analysed. However, the most important result of our study is the observation that the endothelium is functioning at least to the extent that vasodilatation occurs. The relative response of proximal segments in diseased and normal arteries is of less significance.

Differential reactivity between proximal and distal segments, particularly when expressed as percentage change, has been found in response to many vasoactive stimuli and appears to be an inherent characteristic of human coronary arteries which is not disease dependent. This differential activity could reflect a difference in the ratio of the endothelial cells to smooth muscle cells. On average the distal segments of diseased vessels respond similarly to those of "normal" vessels, indicating that endothelial function is mainly preserved. However, the response of distal segments of arteries with a poor proximal segment response is less than "normal," indicating that more severe forms of the disease do involve some impairment of distal vessel endothelial function.

The finding in our study of a reduced response to substance $\mathrm{P}$ in the proximal segments of diseased vessels could be taken as further evidence of impaired endothelial function caused by atherosclerosis. However, the results show that the response to glyceryl trinitrate is also impaired in these diseased segments, and furthermore this impairment of the response to glyceryl trinitrate is similar in magnitude to the response to substance $P$. When the substance P response is expressed as a percentage of the glyceryl trinitrate response it becomes clear that approximately $80 \%$ of response to glyceryl trinitrate can be obtained by giving substance $P$. In fact the diameter of the vessel after substance $\mathrm{P}$ was approximately $95 \%$ of the diameter after glyceryl trinitrate. Therefore, the results of our study are consistent with preserved endothelial function. Furthermore, they are also consistent with the results of Schachinger and Zeiher, ${ }^{16}$ who showed, using angiography and intracoronary ultrasound, that basal coronary vasomotor tone in patients with coronary artery disease was inversely related to atherosclerotic plaque load. 
The reduced vasomotor tone and preserved response to substance $\mathrm{P}$ in atherosclerotic coronary artery segments is consistent with preservation of local vasodilator mechanisms. As atheromatous plaques show neovascularisation on histological examination, it is possible that endothelial cells in these vessels provide a source of relaxing factor such as nitric oxide ${ }^{41-44}$ which could respond to stimulation by substance $\mathrm{P}$. As a compensatory mechanism for loss of epicardial vessel endothelial cells at the site of atherosclerotic plaque, a functional remodelling process appears to occur and this may depend partly on preserved nitric oxide synthase activity. In a recent experimental study, ${ }^{45}$ it was shown that chronic inhibition of nitric oxide causes coronary vascular remodelling, vascular fibrosis, and medial thickening.

\section{CONCLUSION}

The results of this study provide evidence of partial preservation of endogenous endothelium dependent vasodilator mechanisms in atherosclerotic coronary arteries.

1 Furchgott RF, Zawadski JV. The obligatory role of endothelial cells in the relaxation of arterial smooth muscle by acetylcholine. Nature 1980;288:373-6.

2 Vanhoutte PM. The endothelium. Modulator of vascular smooth muscle tone. N Engl f Med 1988;319:512-13.

3 Vane JR, Anggard EE, Botting RM. Regulatory functions of the vascular endothelium. N Engl f Med 1988;319:512-13.

4 Griffith TM, Edwards DH, Lewis MJ, et al. The nature of endothelium-derived relaxing vascular factor. Nature 1984; 308:645-7.

5 Hutchinson PJA, Palmer RMJ, Moncada S. Comparative pharmacology of EDRF and nitric oxide on vascular strips. Eur 7 Pharmacol 1987;141:445-51.

6 Christie MI, Griffith TM, Lewis MJ. A comparison of basal and agonist-stimulated release of endothelium-derived and agonist-stimulated release of endothelium-derived
relaxing factor from different arteries. $\mathrm{Br} \mathcal{7}$ Pharmacol relaxing factor from

7 Boulanger C, Hendrickson H, Lorenz RR, et al. Release of different relaxing factors by cultured porcine endothelial cells. Circ Res 1989;64:1070-8

8 Shikano K, Ohlstein EH, Berkowitz BA. Differential sensitivity of endothelium-derived relaxing factor and nitric oxide in smooth muscle. Br f Pharmacol 1987;92:483-5.

9 Feletou M, Vanhoutte PM. Endothelium-dependent hyperpolarisation of canine coronary smooth muscle. $\mathrm{Br}$ F Pharmacol 1988;93:515-24.

10 Forstermann U, Mugge A, Alheid U, et al. Selective attenuation of endothelium-mediated vasodilation in atherosclerotic human coronary arteries. Circ Res 1987;62:185-90.

11 Ludmer PL, Selwyn AP, Shook TL, et al. Paradoxical vasoconstriction induced by acetylcholine in atherosclerotic
coronary arteries. N Engl f Med 1986;315:1046-51.

12 Golino P, Piscione F, Willerson JT, et al. Divergent effects of serotonin on coronary artery dimensions and blood flow in patients with coronary atherosclerosis and control patients. patients with coronary atheroscler

13 Panza JA, Quyyumi AA, Brush JE, et al. Abnormal endothelium-dependent vascular relaxation in patients with essential hypertension. $N$ Engl F Med 1990;323:22-7.

14 Zeiher AM, Drexler H, Wollschlager H, et al. Modulation of coronary vasomotor tone: progressive endothelial dysfunction with different early stages of coronary atherosclerosis. Circulation 1991;83:391-401.

15 Forstermann U, Mugge A, Alheid U, et al. Endothelium derived relaxing factor (EDRF): a defence mechanism against platelet aggregation and vasospasm in huma coronary arteries. Eur Heart $\mathcal{f}$ 1989;10 (suppl F):36-43.

16 Schachinger V, Zeiher AM. Quantitative assessment of coronary vasoreactivity in humans in vivo: importance of baseline vasomotor tone in atherosclerosis. Circulation 1995;92:2087-94.

17 Enokibori M, Okamura T, Toda N. Mechanism underlying substance P-induced relaxation in dog isolated superficial temporal arteries. Br $\mathcal{F}$ Pharmacol 1994;111:77-82.

18 Petersson J, Zygmunt PM, Brandl L, et al. Substance $\mathrm{P}$-induced relaxation and hyperpolarization in human cerebral arteries. Br F Pharmacol 1995;115:889-94.
19 Ralevic V, Khalil Z, Helme RD, et al. Role of nitric oxide in the actions of substance $\mathrm{P}$ and other mediators of inflammation in rat skin microvasculature. Eur 7 Pharmacol 1995;284:231-9.

20 Kuroiwa M, Aoki H, Kobayashi S, et al. Mechanism of endothelium-dependent relaxation induced by substance $\mathrm{P}$ in the coronary artery of the pig. Br F Pharmacol 1995;116: 2040-7.

21 Ziche M, Morbidelli L, Masini E, et al. Nitric oxide mediates angiogenesis in vivo and endothelial cell growth and migration in vitro promoted by substance P. F Clin Invest 1994;94:2036-44.

22 Crossman DC, Larkin SW, Fuller RW, et al. Substance P dilates epicardial coronary arteries and increases coronary blood flow in humans. Circulation 1989;80:475-84.

23 Crossman DC, Larkin SW, Dashwood MR, et al. Responses of atherosclerotic coronary arteries in vivo to the endothelium-dependent vasodilator substance P. Circulation 1991;84:2001-10.

24 Reiber JHC, Serruys PW, Koouman C, et al. Assessment of short-, medium, and long-term variations in arterial diment, medium, and long-term variations in arterial dimensions from computer-assisted quantitation

25 Tousoulis D, Davies G, McFadden E, et al. Coronary vasomotor effects of serotonin in patients with angina. Relationship to coronary stenosis morphology. Circulation 1993;88(part 1):1518-26.

26 Weihe E, Reinecke M, Opherk D, et al. Peptidergic innervation (substance P) in the human heart. $\mathcal{F}$ Mol Cell Cardiol 1981;13:331-3.

27 Kilpatrick EV, Cocks TM. Evidence for differential roles of nitric oxide (NO) and hyperpolarization in endotheliumdependent relaxation of pig isolated coronary artery. $\mathrm{Br} \mathcal{F}$ Pharmacol 1994;112:557-65.

28 Bull HA, Hothersall J, Chowdhury N, et al. Neuropeptides induce release of nitric oxide from human dermal microvascular endothelial cells. F Invest Dermatol. 1996;106:655-60.

29 Cockcroft JR, Chowienczyk PJ, Brett SE, et al. Effect of NG-monomethyl-L-arginine on kinin-induced vasodilation in the human forearm. Br $\mathcal{f}$ Clin Pharmacol 1994;38:307-10.

30 Chester AH, O’Neil GS, Moncada S, et al. Low basal and stimulated release of nitric oxide in atherosclerotic epicardial coronary arteries. Lancet 1990;336:897-900.

31 Vanhoutte PM, Auch-Schwelk W, Biondi ML, et al. Why are converting-enzyme inhibitors vasodilators? Br F Pharmacol 1989;28:95-104S.

32 Zeiher AM, Drexler H, Wollschlaeger H, et al. Coronary vasomotion in response to sympathetic stimulation in humans: importance of the functional integrity of the endothelium. f Am Coll Cardiol 1989;14:1181-90.

33 Kushwaha SS, Crossman DC, Bustami M, et al. Substance $P$ for evaluation of coronary endothelial function after cardiac transplantation. $\mathcal{F}$ Am Coll Cardiol 1991;17:1537-44.

34 Brown BG, Bolson E, Petersen RB, et al. The mechanisms of nitroglycerin action: stenosis vasodilatation as a major component to the drug response. Circulation 1981;64: 1089-97.

35 Brown BG, Bolson EL, Dodge HT. Dynamic mechanisms in human coronary stenosis. Circulation 1984;48:797-803. 36 Tousoulis D, Kaski JC, Bogaty P, et al. Reactivity of proximal and distal angiographically normal and stenotic coronary segments in chronic stable angina pectoris. Am $\mathcal{F}$ Cardiol 1991;67:1195-200.

37 Quyyumi A, Mulcahy D, Andrews NP, et al. Coronary vascular nitric oxide activity in hypertension and hypercholesterolemia. Comparison of acetylcholine and substance P. Circulation 1997;95:104-10.

38 Cox DA, Vita JA, Treasure CB, et al. Atherosclerosis impairs flow-mediated dilation of coronary arteries in humans. Circulation 1989;80:458-65.

39 Kaski JC, Tousoulis D, Gavrielides S, et al. Comparison of epicardial coronary artery tone and reactivity in Prinzmetal's variant angina and chronic stable angina pectoris. $7 \mathrm{Am}$ Coll Cardiol 1991;17:1058-62.

40 Feldman RL, Marx D, Pepine CJ, et al. Analysis of coronary responses to various doses of intracoronary nitroglycerin. Circulation 1982:66:321-7.

41 Tousoulis D, Davies GJ, Tentolouris C, et al. Effects of inhibition of nitric oxide synthesis in patients with coronary artery disease and stable angina. Eur Heart $\mathcal{F}$ 1997;18:60813.

42 Tousoulis D, Crake T, Davies GJ, et al. Basal nitric oxide production by diseased coronary arteries. $\mathcal{F} \mathrm{Am}$ Coll Cardiol 1996;28:1639

43 Tousoulis D, Tentolouris C, Crake T, et al. Basal and flowmediated nitric oxide production by atheromatous coronary arteries. 7 Am Coll Cardiol. 1997;29:1256-62.

44 Buttery LDK, Springall DR, Chester AH, et al. Inducible NO synthase is present within human atherosclerotic lesions and promotes the formation and activity of lesions and promotes the formation
peroxynitrite. Lab Invest 1996;75:77-85.

45 Numaguchi $\mathrm{K}$, Egashira K, Takemoto $\mathrm{M}$, et al. Chronic inhibition of nitric oxide synthesis causes coronary microvascular remodeling in rats. Hypertension 1995;26(part 1):957-62. 